\title{
“JOGA PEDRA NA GENI: A ESCOLA É FEITA PRA APANHAR, ELA É BOA DE CUSPIR! (?)"
}

\author{
"THROW STONES AT GENI: SCHOOLS ARE MEANT TO BE \\ RIDICULED, HOW GOOD ARE THEY AT FIGHTING BACK? "1
}

\author{
(iD) Luciano Carlos Mendes de Freitas Filho \\ Doutor em Educação pela UFRJ \\ Professor do Instituto Federal da Bahia/IFBA. \\ Valença, Bahia- Brasil. \\ luciano_freitas@hotmail.com
}

\begin{abstract}
Resumo: Opero nesse texto com a ideia de pensar a escola brasileira contemporânea, sobretudo a pública, a partir da personagem Geni, da canção "Geni e o Zepelim" de Chico Buarque de Hollanda. Trata-se de uma analogia com a intenção de problematizarmos as investidas atuais voltadas a essa instituição, a partir de demandas políticas de grupos sociais diversos, na tentativa de controle dos significantes currículo e docência, na luta pela fixação de sentidos hegemônicos do que entendem por escola democrática. Esse texto faz parte de estudos desenvolvidos no campo pósestruturalista, sobretudo relacionado às políticas curriculares, e aposta na escola enquanto espaço-tempo em meio a processos de subjetivação e vivências de experiências contínuas, um espaço em que emergem zonas de escape e/ou atos de resistências na busca de se permitir ser espaço do plural, de ser enquanto Geni, sendo o que é na diferença, "em sua dor e delícia". Por mais que haja uma posição privilegiada dos formuladores da política, instituindo-se em macropoder, entretanto, no chão da escola, os sujeitos da educação (estudantes, professores, técnicos e auxiliares administrativos) reconfiguram e/ou recontextualizam a política no contexto da prática escolar.
\end{abstract}

Palavras-chave: currículo; demandas políticas; disputas; escola democrática; práticas docentes.

Abstract: I operate in this text with the idea of thinking about the contemporary Brazilian school, especially the public one, based on the character Geni, from the song "Geni e Zepelim" by Chico Buarque de Hollanda. It is an analogy with the intention of problematizing the current attacks on this institution, based on the political demands of diverse social groups, in an attempt to control significant curriculum and teaching in the struggle to fix hegemonic meanings of what they mean by school. democratic. This text, which is intended to be post-structural, is part of my PhD studies in Education and affirms the school as space-time immersed in processes of subjectification and experiences of continuous experiences that allow areas of escape and / or acts of resistance to perceive itself as a space of the plural, as Geni, being what it is in the difference, "in its pain and delight". As much as there is a privileged position of policy makers, within the macro-power scope, however, on the school floor, the subjects of education (students, teachers, technicians and administrative assistants) reconfigure and/or recontextualize the policy in the context of school practice.

Keywords: curriculum. politic demands. disputes. democratic school. teaching practices.

\section{Para citar - ABNT NBR 6023:2018}

FREITAS FILHO, Luciano Carlos Mendes. "Joga pedra na Geni: a escola é feita pra apanhar, ela é boa de cuspir! (?)”. Cadernos de Pósgraduação, São Paulo, v. 20, n. 2, p. 135-149, jul./dez. 2021. Disponível em: https://doi.org/10.5585/cpg.v20n2.20147.

${ }^{1}$ Geni, from "Geni e o Zeppelin”, is a Brazilian song composed by Chico Buarque de Hollanda, for his 1978 album. The song has a relevance by the time it discusses about a transsexual woman who is a prostitute, suffering moral persecutions from the local society. 


\title{
1 Situando o texto: considerações iniciais
}

Esse texto tem por objetivo pensar a escola brasileira contemporânea, sobretudo a pública, a partir da personagem Geni, da canção "Geni e o Zepelim” de Chico Buarque de Hollanda. Apresento essa analogia com a intenção de problematizar as tensões provocadas pelas investidas de grupos sociais diversos diante da escola. Diz respeito a tensionamentos, provocados por múltiplas demandas políticas, na tentativa de controle dos significantes currículo e docência para uma fixação de sentidos hegemônicos do que entendem por escola democrática.

Tem sido uma constante em minhas reflexões problematizar cenários atuais em que a escola brasileira tem sido objeto de críticas e interpelações diversas acerca de sua função e/ou papel social. Em texto anterior (FREITAS FILHO, 2019), problematizo discursos por parte de setores diversos da sociedade que afirmam uma escola obsoleta e em crise. Na esteira das reflexões propostas por Masschelein \& Simons (2017), observo como a escola tem sido acusada de ser "um maquinário normalizador, colonizador e alienante, que impõe, estabelece e reproduz mais ou menos violentamente certa ordem social”. (MASSCHLEIN \& SIMONS, 2017, p 19).

Venho ressaltando que

\begin{abstract}
Um dos efeitos dessa crise e da "enxurrada" de críticas consiste no aumento de discursos favoráveis ao esvaziamento da escola, a um discurso de 'não escolarização' e estímulo ao ensino não-presencial. Por sua vez, essas críticas vêm acompanhadas de proposições e/ou projetos que demandam interdições ou controles ao conteúdo escolar, às reflexões diversas no campo epistemológico que defendem o fluxo da criticidade, à liberdade de cátedra dos professores etc. (FREITAS FILHO, 2019, p.2) .
\end{abstract}

Entretanto, como contraponto, tenho insistindo em trazer para o debate -muitas vezes parecendo uma repetição de um mantra político-pedagógico- a defesa da escola, sobretudo da pública. Afinal, conforme reitera Larrosa (2017) "reconhecer que a aprendizagem ultrapassa as fronteiras da escola e se dá em diversos lugares e em quaisquer momentos, não implica no esvaziamento dela" (LARROSA, 2017, prefácio).

Quando exponho a intenção de refletir sobre essas interpelações contemporâneas à escola, a partir de múltiplas demandas de grupos políticos diversos - com maior ênfase no controle do currículo escolar e das práticas docentes- não busco afirmar que são disputas inauguradas na esteira do tempo atual,

Diversos estudos teóricos anteriores se voltaram a refletir a escola como aparelho ideológico e espaço de disputa para dominação e controle, assim como para pensar as disputas pelo currículo escolar - a destacar os estudos de autores como Althusser (1971), estudos marxistas e aqueles de investidas teóricas do campo da Teoria Crítica e pósestruturalista para pensar currículo, entre outros estudos -. (FREITAS FILHO, 2021) 
Por outro lado , demarco como o contexto da prática escolar contemporânea, da escola brasileira das 2 (duas) últimas décadas, tem apresentado investidas e ameaças de interdição, cotidianamente, por parte de grupos políticos distintos - com destaque aos grupos religiosos, político-partidários e empresariais- e que apresentam demandas e/ou exigências peculiares na perspectiva de disputar esse espaço, fixando sentido sobre o que entendem e defendem por escola democrática, a partir do pretenso controle do currículo e das práticas docentes. São investidas que apresentam especificidades/particularidades no contexto do tempo em curso, na medida em que refletimos sobre projetos de lei que visam definir o que ensinar, quem ensinar e como ensinar.

Em recente texto (FREITAS FILHO, 2021), destaquei que as demandas políticas, no cenário atual, geralmente têm sido acompanhadas por intimidações distintas, com ameaças de, por exemplo, imputar multas a professores ou restringir suas liberdades de cátedra com advertências de exoneração/demissão ou por meio de um controle e restrição às aquisições de materiais didáticos relacionados aos debates sobre direitos humanos, tal qual com ameaças de filmagens de aula de professor por parte de alunos, por parte de pais e mães e membros da comunidade escolar ou a partir da ampliação de discursos que defendem a militarização de escolas públicas, entre outras questões.

Demandas de ordens diversas e que se configuram a partir de tramas políticas igualmente diversas, a saber: Projeto Escola sem Partido/EsP, Educação Domiciliar/Homeschooling, militarização de escolas públicas e escolas indígenas e Ensino Fundamental a distância, entre outros.

$\mathrm{Na}$ medida em que aponto as disputas de sentidos de escola democrática a partir das tentativas de controle dos significantes currículo e docência, não estou dizendo que não existam outras possibilidades de investidas no interior dessa instituição, cito, por exemplo, as potenciais viabilidades de investidas no campo da avaliação ou da formação de professores. Todos esses campos estão, de certa forma, interligados. Contudo demarco o objetivo do texto, ao perceber uma maior e mais forte atuação na interpelação às políticas curriculares e aos sentidos do que se entende por ser professor, sobre o que ensinar e como ensinar, em suma, sobre a categoria docência, no contexto do hoje.

Interessa-me, em suma, sublinhar os interesses que levam diversos setores da sociedade civil e governamentais a criarem tanta expectativa frente a escola e, dessa forma, apresentarem diversas demandas no intuito de disputar seu "terreno", particularmente, no que diz respeito aos efeitos dessas disputas nos processos de significação de termos como currículo e docência. Como e por quais razões essas demandas discursivas diversas podem se tornar exigências políticas e, por conseguinte, podem ser produzidas em meio a articulações sociais a partir de proposições de intervenções, vetos e 'vigilância e punição' (FOUCAULT, 1987). 
Todo esse debate sobre as disputas e negociações para fixar hegemonizações no espaço escolar, reitera as influências que o contexto da prática (BALL, 199²) exerce sobre as políticas educacionais, principalmente as curriculares.

Reforço nesse texto, assim, que o debate sobre a dinâmica da recriação no/do social, particularmente no espaço escolar, evidencia também a potência da lente teórica pós-estruturaliasta, sobretudo aquelas que se debruçam a partir de escopos teóricos problematizados pelo viés da discursividade, para pensar currículo e docência no contexto da prática.

\section{A escola como Geni: "maldita e bendita"}

A crise da educação no Brasil não é uma crise, é um projeto. Darcy Ribeiro

Reafirmo a emergência do debate sobre como certas demandas políticas voltadas à escola brasileira, sobretudo à escola pública, são afetadas pelas práticas da diferença no social e, dessa forma, podem se apresentar nas disputas discursivas sob a forma de exigências e, por conseguinte, virem acompanhadas por propostas de punições, vetos ou interdições.

Intenciono problematizar sobre como os movimentos percorridos por tais exigências podem ser produzidas no contexto da prática, na escola, por meio das interpelações às políticas curriculares e às práticas docentes.

A título de maior esclarecimento, tomo como exemplo os discursos existentes no Projeto Escola sem Partido ${ }^{2}$ Demandas discursivas que alegam a defesa de uma democratização a partir do enfrentamento a uma pretensa neutralidade docente e à "doutrinação ideológica" e que, mais adiante, apresentam essas mesmas demandas sob forma mais incisiva, por meio de reivindicações que geralmente têm vindo acompanhadas por ameaças de censura, vetos, punições diversas - como por exemplo, a tentativa de proibição das discussões freireanas ou marxistas em aulas dos componentes curriculares diversos, tendo a advertência de aplicação de multas ou inquéritos para a exoneração de professores que porventura venham a 'encampar' esse debate- ou seja, a materialização de um cenário educacional de exceção (FRIGOTTO, 2017).

Faz-se necessário, entretanto, explicitar as razões pelas quais intitulamos o texto "Joga pedra na Geni: a escola é feita pra apanhar, ela é boa de cuspir! (?)”, inclusive apresentando esse título ora como uma afirmação, ora como um questionamento.

Trata-se de uma referência ao texto/letra de "Geni e o Zepelim", uma das canções mais divulgadas e de maior sucesso da peça Ópera do Malandro, musical de 1977/1978 de Chico

\footnotetext{
${ }^{2}$ O projeto de lei 867/2015, que dispunha sobre o Escola sem Partido/EsP, embora tenha sido arquivado em 2019, no âmbito da Câmara Federal, ainda tem sido pautado por meio de outros projetos de lei escritos à luz do que o texto do EsP propunha.
} 
Buarque de Hollanda. Paula e Figueiredo (2010) destacam como a canção fazia bastante sucesso nas rádios na época, sendo uma das músicas mais populares do álbum lançado um ano após a estreia da peça. "Crítica à hipocrisia e ao poder, ela se destacou nos "anos de ferro", em plena ditadura militar no Brasil" (PAULA \& FIGUEIREDO, 2010, p.1).

Ainda segundo as autoras (2010), todas as rádios tocavam e a população cantava em coro os refrões da canção, "nem sempre com a compreensão da unidade estética crítica da mesma, uma vez que a crítica se revela ao considerar toda a narrativa da canção e não apenas o refrão, que parece acusar a sua protagonista”. (PAULA \& FIGUEIREDO, 2010, p. 1).

Genivaldo, com nome social Geni, é uma travesti que, na verdade, é a heroína injustiçada do enredo. É o corpo que revela o preconceito e a hipocrisia de toda a cidade com a heroína prostituída e ameaçada de apedrejamento, tal como 'Maria Madalena'. Ao mesmo tempo que Geni serve aos deleites dos homens da cidade, em que toda sua formosura serve de alento e "uso", por outro lado seu próprio corpo e a expressão dele é passível do desprezo de toda a cidade.

A letra da canção diz respeito a uma cidade que, certo dia, recebe a visita ameaçadora de um comandante militar vindo em seu zepelim. Ele, ao se deparar com tanta miséria e ‘horrores' no local, decide destruir aquele povoado.

"Um dia surgiu, brilhante, entre as nuvens, flutuante, um enorme zepelim. Pairou sobre os edifícios, abriu dois mil orifícios, com dois mil canhões assim ...”

(...)A cidade apavorada, se quedou paralisada, pronta pra virar geleia Mas do zepelim gigante, desceu o seu comandante, dizendo: "Mudei de ideia!"

Contudo, mesmo ameaçando a cidade, ele afirma que pode mudar de ideia e deixar o povoado sem causar quaisquer danos, caso a jovem prostituta Geni conceda a ele uma noite 'em seus aposentos'.

\footnotetext{
"Quando vi nesta cidade, tanto horror e iniquidade, resolvi tudo explodir Mas posso evitar o drama, se aquela formosa dama, esta noite me servir."

"Essa dama era Geni! Mas não pode ser Geni! Ela é feita pra apanhar Ela é boa de cuspir, ela dá pra qualquer um, maldita Geni!"

"Mas de fato, logo ela, tão coitada e tão singela, cativara o forasteiro O guerreiro tão vistoso, tão temido e poderoso, era dela, prisioneiro."
}

Geni, um 'poço de bondade', que antes era recriminada, julgada por sua sexualidade e por sua profissão, cuspida e ameaçada constantemente de apedrejamento, passa a ser assediada pelo bispo, prefeito e pelo banqueiro da cidade para que ceda à demanda do comandante e, assim, salve a cidade. Geni, não vendo outra saída, cede às reivindicações das pessoas de sua cidade e, dessa forma, consegue o feito de afastar o comandante e manter a ordem e a paz, passando a ser aclamada como "Bendita Geni!". 
"Acontece que a donzela (e isso era segredo dela), também tinha seus caprichos. E ao deitar com homem tão nobre, tão cheirando a brilho e a cobre, preferia amar com os bichos."

"Ao ouvir tal heresia, a cidade em romaria, foi beijar a sua mão O prefeito de joelhos, o bispo de olhos vermelhos, e o banqueiro com um milhão."

"Vai com ele, vai, Geni! Vai com ele, vai, Geni! Você pode nos salvar, você vai nos redimir, você dá pra qualquer um, bendita Geni!"

"Foram tantos os pedidos, tão sinceros, tão sentidos, que ela dominou seu asco. Nessa noite lancinante, entregou-se a tal amante, como quem dá-se ao carrasco".

No dia seguinte, aquele corpo "bendito", depois de sua serventia, volta a ser maldito, passível de receber "bosta, pedra e cuspe", por tentar ser o que é, na prática de seu gênero e de sua sexualidade. Um corpo na/da diversidade.

\footnotetext{
"Num suspiro aliviado, ela se virou de lado e tentou até sorrir. Mas logo raiou o dia, e a cidade em cantoria, não deixou ela dormir, joga pedra na Geni! joga bosta na Geni! Ela é feita pra apanhar! Ela é boa de cuspir! Ela dá pra qualquer um! Maldita Geni!
}

De vilã à heroína, e heroína à vilã, Geni, a jovem prostituta da narrativa em questão, me serve para pensar a escola corporificando-se a partir dessa personagem.

Ao propor uma analogia da escola enquanto Geni, não estou destacando esse espaço escolar na condição do lugar do ato de se prostituir ou perspectivas afins. Muito menos proponho pensar Geni como referência a toda e qualquer escola, em todo e qualquer recorte de tempo.

$\mathrm{Na}$ verdade, essa proposta de análise comparativa busca pensar uma forma de ver a escola brasileira contemporânea constantemente posta a cerceamentos e interpelações diversas, em meio às contingências que circulam ao redor desse "espaço-tempo" educacional, por parte de demandas políticas diversas. Na medida em que problematizo a escola dessa forma, exponho sentidos de uma escola por vezes vilipendiada, de uma escola que, ao mesmo tempo que é criticada, acusada de fracassada e em crise, é a mesma que sofre pressão e ameaças constantes para atendimento de reivindicações diversas para servir a todos, para múltiplos fins.

A escola quando abre espaço para atender demandas, sejam elas de quaisquer grupos políticos, ela passa a ter serventia e o devido valor. Quando não atende às demandas diversas ou quando as políticas curriculares ou práticas docentes incomodam, ela passa a ser alvo de exigências e propostas de interdições, de reformas e, algumas vezes, ameaças de disciplinamento. Um corpo a ser vigiado, disciplinado e passível de punição.

Um olhar para a escola brasileira contemporânea, sobretudo a pública, dessa forma, não é negar que vem de outrora esses mesmos discursos de vigilância e punição, de tentativas de 
aparelhamento ou de disciplinamento. Contudo, é perceber que avanços alcançados -mais particularmente ao que me interessa pensar nesse texto, avanços relacionados ao campo do currículo e da docência em função do fomento de uma escola democrática- promovem reações ou discursos reacionários (PENNA, 2017).

Ainda referindo-me à letra da canção, destaco a presença de 3 (três) personagens "ilustres" da cidade de Geni, para que possamos pensar a existência de micropoderes distintos que interpelam essa escola da qual discorro: o banqueiro, que na nossa discussão representaria os discursos e demandas por parte de reformadores empresariais; o bispo, representando os discursos religiosos 'volta e outra' pairando sobre a escola, e o prefeito, representando nesse texto a ideia dos discursos e demandas por parte dos partidos políticos.

Atos de poder que no cenário atual equivalem a práticas discursivas entremeadas por projetos diversos em disputa no contexto político, a saber: implementação de uma política de militarização de escolas públicas; o fomento das propostas do movimento Escola sem Partido e do homeschooling por parte, sobretudo, da bancada religiosa na Câmara e no Senado e pela gestão do governo federal, e as investidas dos reformadores empresariais em torno das discussões curriculares, de uma maior inserção do ensino híbrido, das reformas do currículo e de uma maior perspectiva de discursos neotecnicistas, de abertura ao ensino para pessoas com notório saber e certa ênfase nas avaliações de larga escola e na responsabilização (accountability) de professores, por exemplo.

Fazer comparativos sobre como a mesma escola criticada e julgada, pode ser a mesma escola em que políticos e outros sujeitos da sociedade apontam como uma salvação, caso suas demandas sejam atendidas, reforça a ideia das disputas contínuas pela fixação de sentidos na busca do controle do social. Para a escola deixar de ser maldita" é preciso superar a crise, se abrir a propostas de mudanças e reformas concernentes aos interesses de grupos políticos diversos e, dessa forma, se redimir, se tornando uma "bendita Geni".

É essa mesma escola, aparentemente em crise e imersa em conflitos e enfrentamentos diversos, que pode resistir. Nesse sentido, ao trazer o título do texto sugerindo um questionamento “Joga pedra na Geni: a escola é feita pra apanhar, ela é boa de cuspir! (?), permito a possibilidade de responder/compreender que a escola não é feita pra apanhar, nem boa de cuspir.

Reconhecer a realidade de crise de muitas escolas públicas, baixos desempenhos, violências etc., nos impulsiona a repensar ou ressignificar as formas de dar sentido e vivenciar a escola, do fazer pedagógico, contudo, sem abrir mão dessa instituição enquanto espaço estratégico para o ensino-aprendizagem. 
Se tomarmos por base os discursos que circulam em mídias jornalísticas, por exemplo, podemos perceber como uma mesma escola que apresenta diversos avanços ou esforços para sua melhoria e para uma vivência de práticas democráticas, pode ser a mesma escola julgada e criticada, acusada e ameaçada de "cuspidas e apedrejamentos", caso apresente quaisquer falhas mesmo que algumas dessas dificuldades ou "fracassos escolares possam estar relacionadas à falta de maiores investimentos de recursos públicos, por exemplo-. Tem sido muito mais conveniente, ultimamente, passível de maior acesso público, notícias sobre fracassos escolares que aquelas que enfatizam as experiências ou vivências bem-sucedidas, inclusive em postagens de redes sociais .

Quando destaco as possibilidades de resistência da escola, suas potencialidades de criação, estou demarcando apostas de ver esse espaço e seus processos de escolarização a despeito das interpelações diversas que se apresentam em forma de exigências ou proposições de interdições, censuras e vetos. Não nego entender a escola como espaço social que deve ser ou estar aberta à comunidade, às relações com diversos setores sociais, aberta ao dissenso e aos conflitos e negociações discursivas salutares ao processo democrático. Entretanto, resgato a defesa de entender a escola a despeito de discursos de cerceamentos ou disciplinamentos por meio de tentativas de interdição, silenciamento e censura .

Pensar a escola como um espaço por vezes 'Geni', acusado, criticado e, ao mesmo tempo, desejado/disputado, nos leva a considerar a sua defesa e o seu elogio e a reiterar um espaço de diálogo com a diversidade, com o contraditório, fazendo emergir questões estratégicas para pensar a disputa de sentidos de currículo e docência e, por conseguinte, a fixação de sentidos por uma escola democrática: Por que defender a escola? Que escola, que currículo, queremos defender? Defender de quê ou de quem? Como defender a docência?

\section{A escola entre os afagos e xingamentos: por uma defesa da escola}

\footnotetext{
"Nós nos recusamos firmemente a endossar a condenação da escola. Ao contrário, defendemos sua absolvição. Acreditamos que é exatamente hoje - em uma época em que muitos condenam a escola como desajeitada à realidade moderna e outros até mesmo parecem querer abandoná-la completamente- que o que a escola é e o que ela faz se torna evidente. ". (MASSCHLEIN \& SIMONS, 2013, p.10)
}

Embora reconheça as negatividades que circulam provisoriamente no interior ou ao redor da escola, faço apostas em um movimento intelectual pela sua defesa (Masschelein \& Simons, 2013) e na defesa dessa defesa (KOHAN,2017). Não se trata, conforme aponta Kohan (2017), de uma apologia desta ou daquela escola, mas da escola como tal, da escola enquanto escola, é um elogio a instituição como tal (LARROSA, 2017).

Em sintonia com Nóvoa (2017), reitero que o excesso de demandas face a esse espaço e uma demasiada expectação, desejo e ambição podem gerar "frustações" diversas, que por sua vez 
geram descontentamentos, críticas e projetos de interdição, de censura, de reformas e, por vezes, argumentos favoráveis à desprofissionalização docente (NÓVOA, 2017) e à desescolarização como política curricular.

Desde sua origem até os dias de hoje, a escola moderna sempre esteve na mira de todos os tipos de táticas, formas de regulação ou sujeição, a fim de servir ou apresentar finalidade outra, que, segundo Masschelein \& Simons (2013) “muitas vezes não é o escolar em absoluto" (MASSCHELEIN \& SIMONS, 2013, p.22).

Em contraponto, provoco meu leitor a pensar "Genis" enquanto espaços-tempos dedicados ao estudo e das múltiplas possibilidades significativas provenientes da relação dos sujeitos com o conhecimento escolar, a escola de um tempo suspenso, uma escola que profana funções sociais atribuídas a ela, tal como "preparação para o mercado de trabalho', por exemplo.

Expressar expectativas assim, muitas vezes, parte de reivindicações ou exigências outras que podem ser pensadas no currículo escolar, entretanto podem não ser parte desse mesmo currículo. Esse é, pois, um 'risco da/em educação'(BIESTA, 2013) , propiciar o que não se espera e não propiciar o que se espera.

Masschelein \& Simons (2013) ressaltam que, embora a escola tenha sempre permanecido como "símbolo de progresso de um futuro melhor, suas origens não são sem máculas. Foi sorte da escola, ao longo da história, ter escapado da censura definitiva por juiz ou júri ou ter sido privada de seu direito de existir" (MASSCHELEIN \& SIMONS, 2013, p. 9).

\footnotetext{
Durante uma grande parte da história, os esforços para punir as transgressões da escola, foram correcionais: a escola era algo a ser constantemente melhorado e reformado. Era tolerada, desde que se submetesse a programas de ajuste ou se dedicasse ao serviço de um conjunto de ideais fixos (políticos e religiosos) e projetos já prontos (a construção da nação, as missões civilizadoras) (MASSCHELEIN \& SIMONS, 2013, p. 9).
}

Em diálogo com Nóvoa (2009), problematizo acerca das expectativas que a escola criou no tocante às missões que adquiriu, em meio às diversas demandas sociais por parte de setores civis e governamentais, ao longo da sua história. De acordo com o autor (2009), "a escola desviou-se muitas vezes das tarefas do ensino e aprendizagem para se dedicar às missões sociais. (NÓVOA, 2009, p. 5).

Em articulação com as reflexões de Nóvoa (2009), Masschelein \& Simons (2013) argumentam sobre as diversas finalidades que à escola foram direcionadas, finalidades não escolares (MASCHELEIN \& SIMONS, 2013).

Resguardando-se os dissensos e/ou perspectivas conflitantes, a ideia de que "é preciso ir à escola para ser alguém na vida" é uma lógica a ser problematizada. A escola não é, necessariamente - ou apenas- , o lugar do assistencialismo, da preparação para o mercado ou de formações 
identitárias. Ademais, problematizo, também, os sentidos de sujeitos referentes a um estudante que ao adentrar na escola já é alguém no espaço-tempo, na vida. O estudante não adentra "despido" do que lhe institui em meio às relações.

Segundo Nóvoa (2009), o excesso de reivindicações e expectativas fixa um sentido de escola, o qual ele denomina de "escola transbordante", ou seja, um excesso de demandas e atribuições voltadas a uma escola que, por conseguinte, impulsiona projetos políticos, acusações de fracasso e crise, e, desse modo, resulta em imposição de vetos e reformas.

No livro "Em defesa da Escola", Masschelein e Simons (2013) discorrem sobre as críticas e acusações à escola mais comuns: alienação, concentração de poder, corrupção, desmotivação, ineficácia, falta de empregabilidade, redundância. Segundo Kohan (2017),

A estratégia dos autores no livro não é responder tais críticas diretamente, senão de modo indireto, mostrando o que é fundamental do escolar; o que todas essas críticas parecem, em comum, desconhecer. Critica-se o afastamento da escola em relação ao mundo quando justamente essa separação é uma condição de possibilidade do escolar. (KOHAN, 2017, p. 593 )

Dessa forma, em reação às demandas impostas à escola, os autores belgas sugerem possibilidades performáticas dessa instituição, a fim de garantir o seu “deixa ser”, ou seja, a escola ser escolar. Dentre essas proposições, destaco: a) suspensão (na escola deixa de operar ou valer o que rege o mundo familiar e social exterior à escola); b) profanação (há na escola uma ressignificação livre e profanadora do que opera no mundo exterior; ela exige a possibilidade de renovar o que é público); c) amor (amadorismo do professor: amor/respeito, atenção, dedicação, paixão impessoal pelo mundo e pelas novas gerações) e d) preparação (na escola importa a preparação pela própria preparação, como estudo e exercício, enquanto formadora de si, sem um fim explícito ou predefinido).

Em diálogo com os autores (2013), endosso a ideia da 'suspensão' e profanação' na escola a partir das reflexões de Biesta (2013), quando nos aponta o processo educativo como um processo do risco, do risco de aprender o que não se espera, aquilo que te move da "zona de conforto", daquilo que está fora do teu contexto familiar ou de outra forma relacional

\footnotetext{
Mesmo que alguém se engaje em formas muito bem-organizadas de aprendizagem, há sempre um risco. Não só existe o risco de que você não aprenda o que queria aprender (e nesse caso você sempre pode processar o provedor). Existe também o risco de que você aprenda coisas que nem teria imaginado que desejaria aprender. E existe o risco de que você aprenda algo que preferiria não aprender - algo sobre si mesmo, por exemplo. Engajar-se em aprender sempre acarreta o risco de que a aprendizagem possa ter um impacto sobre você, de que a aprendizagem possa mudá-lo. Isso significa que a educação só começa quando o aprendente está disposto a correr um risco. Um modo de expressar tal fato é dizer que um dos elementos constituintes da relação educacional é a confiança. (BIESTA, 2013, p. 45)
} 
Ainda em articulação com o Biesta (2012), entretanto a partir de uma discussão sua anterior, existente no texto "Boa educação na era da mensuração", reforço a ideia da 'preparação' proposta por Masschelein \& Simons (2013), da escola como espaço de tempo-livre para as relações com o conhecimento e para um percurso de experiências, sem atuar sob a pressão de finalidades outras, a ela imposta.

Biesta (2012), assim como Nóvoa (2009) demonstra uma total inquietação com os excessos de expectativa e demandas voltadas à escola, um tipo de transbordamento (Nóvoa, 2009) das atribuições e 'quereres' relacionados a este espaço. Para tanto, ele reforça a importância da escola como espaço de qualificação, como um espaço de preparação conforme preconizam Masschelein \& Simons (2013). Para Biesta (2012),

\begin{abstract}
Uma tendência que se inclina a tornar a educação uma forma de terapia mais preocupada com o bem-estar emocional de alunos e estudantes do que com sua emancipação (ECCLESTONE, HAYES, 2008; BIESTA, 2010). O que está desaparecendo do horizonte nesse processo é o reconhecimento de que também importa o que os alunos e estudantes aprendam (BIESTA, 2012, p. 187).
\end{abstract}

Antônio Nóvoa (2009), em seu texto “Educação 2021: para uma história do futuro”, reforça que

\begin{abstract}
A escola deve libertar-se de uma visão regeneradora ou reparadora da sociedade, assumindo que é apenas uma entre as muitas instituições da sociedade que promovem a educação. Nesse sentido, pensar do outro modo o espaço público da educação, através de um aproveitamento das potencialidades culturais e educativas que existem da sociedade e de uma responsabilização do conjunto das entidades públicas e privadas ( NÓVOA, 2009, p. 9)
\end{abstract}

Em outras palavras, o autor nos propõe pensar um outro sentido de escola que não aquele da salvação do mal que aflige a sociedade ou como uma seara assistencialista. Ao dispor dessa reflexão em questão, não nego, assim como todos os autores citados nessa seção, a ideia de ter a escola comprometida com a educação para o trabalho e com o apoio assistencial de crianças, jovens e adultos, por exemplo.

Contudo, estamos reforçando que para as excessivas demandas e 'quereres' voltados à escola, é preciso reconhecer a finalidade ou atribuição fundamental à instituição que é a de preparação/qualificação (MASSCHELEIN \& SIMONS, 2013/BIESTA, 2013), a escola como espaço de tempo livre para estudo e vivências de experiências (MASSCHELEIN \& SIMONS 2013), a escola sendo escolar. 
Caso contrário, a escola passa a ser acusada de fracassada ou em crise e, por conseguinte passa a ser cobrada, demandada por projetos reguladores que instituem vetos, censuras ou podem, sobretudo, estimular a desprofissionalização docente e a desescolarização.

Para Nóvoa (2017), esse jogo de interesses e 'pressões' voltadas à escola data de tempos outros e um dos efeitos mais latentes seria o da tentativa de desprofissionalização docente e do engessamento do currículo escolar, segundo o autor (2017)

Desde o início do século, percebe-se um sentimento de insatisfação, acentuado por políticas de desprofissionalização, de ataque às instituições universitárias de formação docente e de privatização da educação (ZEICHNER, 2010a). Em conjunto, estas tendências configuram "um programa de reforma educacional baseado nos princípios de mercado das economias neoliberais" (NÓVOA, 2017 p. 1109).

Ainda segundo o autor (2017), sobre a desprofissionalização docente

A desprofissionalização manifesta-se de maneiras muito distintas, incluindo níveis salariais baixos e difíceis condições nas escolas, bem como processos de intensificação do trabalho docente por via de lógicas de burocratização e de controlo. O discurso da eficiência e da prestação de contas tem reforçado políticas baseadas em "medidas de valor acrescentado", que remuneram os professores em função dos resultados dos alunos, desvalorizando assim outras dimensões da profissionalidade (DARLING-HAMMOND, 2016). O regresso de ideologias que afirmam a possibilidade de atribuir funções docentes a pessoas que tenham "notório saber" de uma dada matéria, como se isso bastasse, também contribui para o desprestígio da profissão. (2017, p 1109).

A desprofissionalização docente ou desqualificação do docente enquanto tal, a partir da sua substituição por profissionais outros 'de notório saber' ou a tentativa de ensino básico a distânciaa ver como exemplo a proposta de campanha eleitoral do atual presidente, acerca do ensino fundamental a distância-é uma preocupação que apresento diante das demandas que interpelam a escola brasileira contemporânea, conforme explicitado anteriormente.

Quando aponto a defesa da escola (MASSCHELEIN \& SIMONS, 2013) e a defesa dessa defesa (KOHAN, 2017), quero evidenciar que nossa defesa reconhece as crises que pairam sobre a escola e as possibilidades de fracasso escolar, em meio aos processos de aprendizagem. Afinal,

\footnotetext{
Elogiar a escola não é fácil em um clima político e cultural em que a crítica antiescolar é conduzida tanto por lideranças destacadas quanto por seus seguidores (DUSSEL, 2017, p. 87. In LARROSA, 2017, Elogio da escola)

Porém, acreditávamos e ainda acreditamos que vale a pena tentar desterrar as operações radicais e revolucionárias da escola como um arranjo pedagógico muito particular e prático, que surgiu na Grécia, de tornar s coisas públicas e de reunir pessoas e mundo (MASSCHELEIN; SIMONS, 2013, p.145)
}

Talvez, os discursos acusativos de fracasso escolar ou de crise, possam oscilar entre as fronteiras da negatividade para a positividade quando pensamos acerca das potencialidades em 
desestabilizar a escola, pensar outros caminhos e sentidos dela, a partir de seus conflitos, como nos provoca a pensar Gabriel (2016), quando aponta que

\footnotetext{
É teoricamente produtivo explorar a crise da escola pública brasileira como um desses momentos de reativação do político nas lutas pela definição de uma ordem social na qual o que está em jogo são projetos de sociedade e seus entendimentos acerca da possibilidade de construção de uma escola democrática, emancipatória e inclusiva. Desse modo, essa crise pode ser percebida como acirramento de um conflito inerente às lutas pela significação dessa instituição, permitindo pensar a produção de outros sentidos mais ou menos antagônicos. (GABRIEL, 2016, p.114)
}

Em sintonia com a autora (2016), reforço que essa defesa da escola não pressupõe um "fechar de olhos" ante aos desafios postos entre e extramuros desse espaço pedagógico. Pensar a ressignificação do currículo e da docência, sem abrir mão dessas categorias é entender, conforme Nóvoa (2017), que ressignificar a escola, seu currículo e seu fazer pedagógico, implica em "reconhecer a existência de um problema. Para quem defende, por exemplo, que as estruturas atuais de formação de professores são adequadas e que o único "problema" é a falta de apoio, de condições ou de recursos, a mudança não se faz necessária”. (NÓVOA, 2017, p.1111).

\section{Considerações finais}

Afirmo pensar a escola como um espaço operando a partir do pensamento de uma democracia radical, reiterando o antagonismo e o conflito como categorias estratégicas do político e afirmando a importância do dissenso como elemento fundamental à democracia.

Uma escola atuando de uma forma que, se ela própria não nos dá a sensação de pertencimento, de acolhimento cultural ou a possibilidade de ir além, em uma relação com o conhecimento escolar, que seja possível pensar numa "paraescola" no interior dessa mesma escola, um lugar dentro do lugar, um lugar da resistência, de processos de identificação de indivíduo e de suas demandas com sua comunidade. A ideia não seria pedagogizar a existência através da escola, mas sim ampliar horizontes dessa existência através dessa escola (LARROSA, 2017).

A escola não está fadada ao fracasso, nem será sempre condicionada à relação de subordinação, assujeitamento e dominação. Ela é e sempre será uma Geni, um corpo diferente, fora do padrão normalizante, um corpo/espaço de contradições, de fissuras, de zonas de escape. Um espaço passível de contínuas resistências e criações, da im-permanência das hegemonias.

É a defesa de pensar a escola de forma afirmativa, como um lugar que tem "uma espécie de alma, um espaço tempo específico no qual é possível uma série de operações concretas, que é preciso entender, e das quais importa tirar toda a potência que esse espaço tempo" (KOHAN, 2017, p. 600). 
A escola é a possibilidade de todos serem alunos. Em meio às 'precariedades da vida' na escola, dela como possível reprodutora ou fomentadora de violências diversas, é possível pensá-la como espaço para potencializar meios que propiciem uma 'vida vivível' (BUTLER, 2018), um espaço de resistência de corpos reunidos em assembleia, coletividade e espaço do antagônico para se pensar um exterior de vida vivível para todos. Espaço que potencializa a simbiose do "eu" com o "nós".

A proposta de defesa da escola permeia a ideia de escola democrática. Não se trata de uma defesa política anarquista, o desprezo aos conteúdos ou de uma postura 'conteudofóbica' (VEIGANETO, 2012). Tampouco de uma proposição que reforça um relativismo, um "tudo pode" na escola. Ao contrário, é pensar que a escola que possibilita tempo livre para estudo, possibilidades de subjetivações e vivência de experiências, a partir de uma relação profunda e simbiótica com o conhecimento escolar, é a mesma escola que não se concebe escolar quando veta a liberdade de cátedra e o pensamento crítico.

Pensar na escola, por vezes, enquanto Geni, é reconhecer os embates cotidianos para ela ser o que é, a despeito das interpelações por práticas que engessam saberes e fazeres.

\section{Referências}

ALTHUSSER, Louis. Ideology and ideological State Apparatuses. New York and London: Monthly Review Press, 1971. 285p.

BIESTA, Gert. Boa educação na era da mensuração. Cadernos de Pesquisa, v. 42, n. 147, p. 808-825, 2012.

BIESTA, Gert. Para além da aprendizagem: Educação democrática para um futuro humano. Belo Horizonte: Autêntica Editora, 2013.

FOUCAULT, Michel. Vigiar e punir. Petrópolis: Editora Vozes, 1987.

FREITAS FILHO, Luciano Carlos Mendes de . Em defesa da escola: reflexões sobre a Educação Domiciliar/Homeschooling. Carta Capital, Justificando, 2019. Disponível em: https://www.justificando.com/2019/03/25/em-defesa-da-escola-reflexoes-sobre-a-educacaodomiciliar-homeschooling.

FREITAS, FILHO, Luciano Carlos Mendes de. A escola buscando ser democrática na contemporaneidade: politicas curriculares sob rasura. Apresentação de trabalho, $40^{a}$ reunião Nacional da ANPEd, outubro, 2021.

FRIGOTTO, GAUDÊNCIO et al. Escola Sem Partido: esfinge que ameaça a educação e a sociedade brasileira. Rio de Janeiro: UERJ, 2017, p. 17-34. FRIGOTTO, Gaudêncio et al. Escola Sem Partido: esfinge que ameaça a educação e a sociedade brasileira. Rio de Janeiro: UERJ, 2017, p. 17-34. 
GABRIEL, Carmen Teresa. Conhecimento Escolar e Emancipação: uma leitura pós-fundacional. Cadernos de Pesquisa [online], v.46, n.156 p.104-130, jan-março, 2016.

KOHAN, Walter Omar. Entre nós, em defesa de uma escola. ETD- Educação Temática Digital Campinas, SP v.19 n.4 p. 590-606 out./dez. 2017

LARROSA, Jorge. Elogio da Escola. Belo Horizonte: Autêntica, 2017.

MASSCHELEIN, Jan \& SIMONS, Maarten. Em defesa da escola. Belo Horizonte: Autêntica, 2013.

MASSCHELEIN, Jan \& SIMONS, Maarten. A pedagogia, a democracia, a escola. Belo Horizonte: Autêntica Editora, 2017.

NÓVOA, Antônio. Educação 2021: Para uma história do futuro. Repositório científico de acesso livre Portugal, 2009. Acessado em: 20/03/2019. Disponível em:

https://repositorio.ul.pt/bitstream/10451/670/1/21232_1681-5653_181-199.pdf

NÓVOA, Antônio. Firmar a posição como professor, afirmar a profissãa docente. Cadernos de pesquisa, v. 47, n. 166, p. 1106-1133. Out/dez, 2017.

PAULA, Luciane de \& FIGUEIREDO, Haber. Geni, a Maria Madalena de Chico Buarque: aclamacões $e$ apedrejamentos na canção e no mundo. Fazendo Gênero 9 Diásporas, Diversidades, Deslocamentos 23 a 26 de agosto de 2010

PENNA, Fernando. O Escola Sem Partido como chave de leitura do fenômeno educacional. In: Escola Sem Partido: esfinge que ameaça a educação e a sociedade brasileira. Rio de Janeiro: UERJ, 2017, p. 35-48.

VEIGA-NETO, A. É preciso ir aos porões. Revista Brasileira de Educação, v. 17, n. 50. maio-ago. 2012 